\title{
LA TELENOVELA BRASILEÑA Y MIJAÍl BAJTÍN: EXTRAPOSICIÓN, AUTORÍA Y GÉNEROS DISCURSIVOS EN ANÁLISIS
}

\author{
ANDERSON LOPES DA SILVA* \\ Grupo de Investigación en Lenguaje y Discurso de los Medios \\ Universidad de São Paulo \\ anderlopps@gmail.com
}

Recibido: 18/11/2020 Aceptado: 5/3/2021

doi: https://doi.org/10.26439/contratexto2021.n035.4972

RESUMEN. Este ensayo aborda los conceptos de extraposición, autoría y géneros discursivos en el estudio de las telenovelas brasileñas. El melodrama Cordel encantado [Cuento encantado], producido y exhibido en el 2011 por la Rede Globo de Televisão, en Brasil, es el objeto empírico de análisis. A su vez, la lectura bajtiniana direcciona la discusión conceptual entre los principios de exceso de visión, autor-creador, autor-persona y géneros discursivos secundarios (todos ellos estudiados dentro del ámbito de la ficción televisiva). Como consideración final, es posible afirmar que el dialogismo de Mijaíl Bajtín (cuando está específicamente reubicado dentro de los medios masivos) revela cómo las ideas de autoría y discurso se resignifican en el complejo tejido melodramático de la telenovela brasileña.

PALABRAS CLAVE: telenovela, discurso, dialogismo, hibridación, Cordel encantado

\section{THE BRAZILIAN TELENOVELAS AND MIKHAIL BAKHTIN: AN ANALYSIS OF OUTSIDENESS, AUTHORSHIP, AND SPEECH GENRES}

ABSTRACT. This essay discusses the concepts of outsideness, authorship, and speech genres in the study of Brazilian telenovelas (soap operas). Its empirical object of analysis is Cordel Encantado (The Enchanted Tale), a melodrama produced and exhibited

\footnotetext{
* Doctor en Ciencias de la Comunicación por la Universidad de São Paulo, Brasil (véase: https://orcid. org/0000-0002-4865-4201)
} 
in 2011 by Rede Globo de Televisão in Brazil. Furthermore, Mikhail Bakhtin's thinking is conducted by the conceptual tension of excess of seeing, author-creator, author-person, and secondary speech genres (analyzed within the scope of television fiction). Finally, it is possible to affirm that Mikhail Bakhtin's dialogism (when specifically relocated inside mass media) reveals how the ideas of authorship and discourse are resignified in the complex melodramatic fabric of the Brazilian telenovela.

KEYWORDS: telenovela / discourse / dialogism / hybridization / Cordel Encantado

\section{A TELENOVELA BRASILEIRA E MIKHAIL BAKHTIN: EXOTOPIA, AUTORIA E GÊNEROS DISCURSIVOS EM ANÁLISE}

RESUMO. Este ensaio aborda os conceitos de exotopia, autoria e gêneros discursivos no estudo das telenovelas brasileiras. 0 melodrama Cordel Encantado, produzido e exibido em 2011 pela Rede Globo de Televisão, no Brasil, é o objeto empírico de análise. Por sua vez, a leitura bakhtiniana direciona a discussão conceitual entre os princípios de excesso de visão, autor-criador, autor-pessoa e gêneros discursivos secundários (conceitos estes que são estudados dentro do âmbito da ficção de TV). Como consideração final, é possível afirmar que o dialogismo de Mikhail Bakhtin (quando realocado especificamente dentro dos meios massivos de comunicação) revela como as ideias de autoria e discurso se ressignificam no complexo tecido melodramático da telenovela brasileira.

PALAVRAS-CHAVE: telenovela / discurso / dialogismo / hibridização / Cordel Encantado 


\section{INTRODUCCIÓN}

La telenovela brasileña es la materialización de un proceso comunicativo abundante, complejo y representativo de las matrices culturales que forman el tejido social nacional. Desde sus inicios, en la década de los cincuenta (con la obra Sua vida me pertence, TV Tupi, 1951) y, con más fuerza, desde Beto Rockfeller (TV Tupi, 1968), la telenovela brasileña no solo es parte de la memoria afectiva y simbólica del público que la ha acompañado por generaciones seguidas, sino que, además, también ha sido objeto de estudio académico muy pertinente para la comprensión de la nación brasileña en sus contradicciones políticas, económicas, sociales y culturales.

Junto al reconocido "modelo brasileño" de producción, discutido por autores como Martín-Barbero (2009), Mazziotti (1993), Santa Cruz (2003) y Borkosky (2016), el formato industrial, adquirido por el modus faciendi de nuestra teledramaturgia, entra diariamente en los hogares de miles de brasileños. Una telenovela que, al combinar los procesos de proyección e identificación en los sujetos que la consumen, también es "amada y odiada" con la misma intensidad por académicos y estudiosos del tema. Es decir, la telenovela provoca posiciones polarizadas en un sentido claro de cómo las diferencias entre "apocalípticos e integrados", en palabras de Umberto Eco, sigue todavía latente en los espacios de investigaciones académicas. Kehl (1986) afirma:

Cotidiana y doméstica, [la telenovela] se convirtió en ese período [1970] en la principal forma de producir la imagen ideal del hombre brasileño. Más específicamente, las telenovelas de las 8 p. m., de Rede Globo, consideradas las más completas y más vistas en la televisión brasileña, cumplieron en la década de 1970 -cuando comenzaron a modernizarse y afirmarse con una estética realista- el papel de ofrecer un espejo glamuroso a los brasileños desarraigados que perdieron su identidad cultural, de forma más cercana a la realidad de su deseo que a la realidad de su vida, y que por eso mismo funcionó como elemento modelador de una nueva identidad, identidad brasileña, identidad-de-los-brasileños, quizás la más parecida a una identidad que este país ya ha tenido. (p. 289)

Treinta y cinco años después de la publicación de Kehl (1986), todavía es posible ver que autores como Lopes y Lemos (2020), Schiavoni (2021) y Lemos y Rocha (2021) destacan la relevancia de las telenovelas para la sociedad brasileña en cuanto a la formación de una memoria e identidad nacionales. Como señalan Lopes y Lemos (2020), incluso en tiempos del streaming, la televisión sigue con fuerza y la telenovela brasileña, en particular, reverbera sus contenidos tanto en la emisión televisiva original como en las formas de consumo que van a internet y redes sociales. La fuerza del discurso televisivo hoy se ve, por ejemplo, en el sector financiero, que aún comprende a la audiencia de la telenovela brasileña como un gran escaparate para exhibir sus productos y servicios en cadena nacional (Lopes y Lemos, 2020, p. 88). 
Así, este artículo propone una lectura de la telenovela brasileña desde el pensamiento dialógico de Mijaíl Bajtín', representado en los conceptos de extraposición, autoría y géneros discursivos. Se tiene en cuenta la dificultad de esta tarea, en particular, debido a la idea ya desgastada de que tales concepciones solo podrían ser analizadas en el campo de la literatura o en el estudio de la novela, un prejuicio, generalmente, irrazonable (Brait, 2008, p. 91). No solo es posible pensar en el dialogismo bajtiniano en los medios actuales, sino que es necesario hacerlo para comprender cuestiones fundamentales como la estética televisiva, la cultura televisiva, la imaginación melodramática y la hibridación cultural en las investigaciones sobre telenovelas (Ribeiro y Silva, 2014). Intelectuales brasileñas y brasileños como Maria de Lourdes Motter (in memoriam), Maria Cristina Palma Mungioli, Daniela Jakubaszko e Igor Sacramento, entre otros, son ejemplos de investigadores que utilizan el marco teórico-metodológico bajtiniano para estudiar las materialidades empíricas de la telenovela brasileña, en particular, y de la teledramaturgia (en otros formatos como series y miniseries), en su conjunto.

Las discusiones mantenidas por estos autores y autoras están, en gran parte, en deuda con los esfuerzos de otros intelectuales que han creado el puente entre los estudios bajtinianos y la comunidad académica, más allá del idioma ruso. Así, los búlgaros Julia Kristeva (1941), con “Bakhtine, le mot, le dialogue, le roman" (1967), y Tzvetan Todorov (1939-2017), con Mikhail Bakhtine: le principe dialogique (1981), se encargaron de introducir y traducir el pensamiento de Bajtín al mundo occidental. Con el dominio de los idiomas ruso y francés, estos autores también fueron los responsables de traducir y crear neologismos basados en términos (relacionados o no) del vocabulario bajtiniano, por ejemplo, extraposición, intertextualidad, translingüística, etcétera (traducciones y neologismos que no siempre son consensuados o bien aceptados en el universo académico), como explican Vauthier y Cátedra (2003). Además de ellos, la investigadora francófona y rusófona Marina Yaguello (1944), con la traducción de Le marxisme et la philosophie du langage (1978), también ha sido responsable por difundir el trabajo de Bajtín/Volóshinov y llevarlo al entorno intelectual occidental (Souza, 2002, pp. 51-53; Zbinden, 2006, p. 12; Sériot, 2015, pp. 22-23). Incluso en Brasil, la recepción de los escritos bajtinianos se produjo, inicialmente, a través de traducciones al francés, ya que, en el contexto fuertemente anticomunista del régimen dictatorial que se vivió en el país entre 1964 y 1985, en muchas ocasiones, "un autor soviético solamente podía ser leído en la traducción occidental" (Schnaiderman, 1983, p. 9).

1 Este trabajo optó por respetar la ortografía original de las traducciones de la lengua española y portuguesa para el nombre del filósofo ruso Михаи́л Миха́йлович Бахти́н (1895-1975). Por lo tanto, en el transcurso de este artículo, el lector encontrará la ortografía Mijaíl Bajtín al hablar del autor en un contexto de discusión dentro del texto y también encontrará la ortografía Mikhail Bakhtin al referirse a las citas que fueron extraídas de las obras del autor traducidas al portugués brasileño. Lo mismo sucede con Валенти́н Никола́евич Воло́шинов (1895-1936): Valentín Volóshinov (en español) y Valentin Volóchinov (en portugués). 
De este modo, con la intención de continuar la tradición de estudiar la telenovela brasileña partiendo de las bases del pensamiento de Mijaíl Bajtín, este artículo propone pensar en el dialogismo bajtiniano como una posición teórica que orienta las discusiones en el campo de los estudios de televisión. Para ilustrar empíricamente esta discusión, se coloca a la telenovela Cordel encantado (en español, Cuento encantado) como el objeto donde se expresan tales lecturas bajtinianas (pero vale la pena mencionar que la matriz analítica de Bajtín es readaptable a cualquier narrativa serial de ficción en la televisión y no solamente al trabajo señalado en este estudio). Esta telenovela, que cumple diez años en el 2021, tuvo una audiencia exitosa y una óptima repercusión en la crítica especializada, además de fomentar la investigación académica en el campo de la comunicación, como demuestran los análisis de Aires (2013) y Silva (2015).

Del mismo modo, este artículo toma el principio bajtiniano de extraposición como posicionamiento metodológico en la relación entre el investigador y su objeto investigado. Por tanto, la extraposición se concibe como el movimiento de distanciamiento-acercamiento del analista que, por medio del exceso de visión, tiene un campo extendido de observación sobre el objeto empírico que estudia (en este caso, la telenovela brasileña). Como posiciones analíticas, a su vez, se ponen en escena cuestiones de autoría (especificadas en la distinción entre autor-persona y autor-creador) para comprender las peculiaridades del tejido teledramatúrgico de Cordel encantado. Finalmente, con un menor grado de importancia analítica, los debates en torno a los géneros discursivos (con un enfoque en la comprensión de los géneros discursivos secundarios) también se abordan en este artículo.

\section{EL DIALOGISMO BAJTINIANO EN LOS MEDIOS DE COMUNICACIÓN: POSICIONAMIENTO TEÓRICO}

Considerar el diálogo como un tejido organizado y estructurado que forma parte de la naturaleza histórica del ser humano nos lleva a entenderlo como el instrumento que transforma la realidad en la lectura del mundo y de la palabra. En este sentido, Mijaíl Bajtín muestra que el papel del lenguaje está basado principalmente en una constitución dialógica. Sus ideas sobre la humanidad y la vida están marcadas por el principio dialógico, que constituye la existencia humana, según el cual la interacción entre sujetos es el principio fundacional, tanto del lenguaje como de la conciencia. Por tanto, el significado y la significación de los signos dependen de la relación entre sujetos y se construyen en la interpretación de los enunciados.

Para Bajtín, el uso del término diálogo no es solamente una mera técnica conversacional o una evolución temático-discursiva capaz de revelar puntos de vista y cosmovisiones: 
El diálogo, en el sentido más estricto del término, es, por supuesto, una de las formas más importantes de interacción verbal, pero no la única. Así, la palabra diálogo puede entenderse en un sentido amplio, es decir, no solo como la comunicación en voz alta de las personas cara a cara, sino como toda comunicación verbal de cualquier tipo. (Bakhtin, 2004, p. 123)

El concepto de dialogismo está, por tanto, en el espacio de interacción entre los sujetos y, como tal, se encuentra el significado atribuido por Bakhtin (2000) al "otro" como relevante en la constitución del significado y en el hecho de que ninguna palabra es la nuestra, sino que trae consigo la perspectiva de otra voz. Es decir, cuando entendemos los medios de comunicación como géneros discursivos secundarios (concepto que será explicado más adelante en este artículo), podemos ver que la construcción de las narrativas televisivas, por ejemplo, está intercalada por voces sociales, o sea, por los valores axiológicos presentes en la sociedad. Y, más allá de los medios, es a través de las mediaciones sociales y de las repercusiones de los contenidos mediáticos entre los destinatarios de una obra que la otredad se hace aún más evidente.

En otras palabras, la comunicación apenas puede existir a partir de relaciones intersubjetivas e interindividuales de sujetos socialmente organizados (por tanto, sujetos involucrados en una unidad social). Según Bakhtin (2004), la conciencia individual sola no puede explicar nada, sino que, por el contrario, debe explicarse ella misma desde el medio ideológico y social. Como afirma el intelectual ruso, solamente a partir de la separación de los fenómenos ideológicos de la conciencia individual podemos conectarlos a las condiciones y a las formas de comunicación social para, a partir de ahí, comprender las materialidades dialógicas del lenguaje. "La existencia del signo no es más que la materialización de esta comunicación y la conciencia individual no es el artífice de esta superestructura ideológica, sino solo un inquilino del edificio social de los signos ideológicos" (Bakhtin, 2004, p. 36).

Es precisamente en la palabra donde se muestran mejor las formas generales básicas e ideológicas de la comunicación de masas. La palabra acompaña a todo acto ideológico. Los procesos de comprensión de todos los fenómenos ideológicos (una pintura, una telenovela, un ritual, un comportamiento humano) no pueden operar sin la participación del discurso interno ${ }^{2}$. Esto no significa, por supuesto, que la palabra pueda

2 Según Hartmann (2007), para Bajtín: “[...] el autodialogismo o incluso el discurso interno [son los] nombres que se le dan al mismo fenómeno discursivo del habla interna, el hablar consigo mismo. Ningún ser humano, en su relación con el lenguaje, escapa a este fenómeno que, de hecho, a lo largo de la vida, es mucho más frecuente que el habla externa. El problema es que se trata de un fenómeno con el que estamos familiarizados, pero que es imposible analizarlo directamente, porque no produce material concreto a nivel del lenguaje. Este hecho no descarta la relación de este fenómeno con el lenguaje. Por tanto, lo que podemos analizar es solo la representación del discurso interno y no el discurso interno en sí" (p. 81). 
suplantar a cualquier otro signo ideológico (Bakhtin, 2004, 2000). Así, queda claro que, incluso con la participación del discurso interno, el proceso no puede ocurrir individualmente, sino en su interlocución entre pares. De esta forma, el lenguaje nunca se usa de manera vaga, sino en un contexto histórico y social donde se interpenetran la enunciación, las condiciones de la comunicación y las estructuras sociales.

De esta forma, al analizar una telenovela, como se hace en este trabajo, nunca podremos desvincular tal ejercicio del contexto de su producción, de la construcción de su mensaje y, desde una perspectiva más especulativa, de las formas de recepción y circulación cultural de este producto mediático. Como dice Machado (2008), pensar en el dialogismo desde los medios de comunicación no es solo transportar formulaciones de un ámbito (como el estudio de la novela) a otro. Al contrario, se trata de redimensionar tales conceptos a través de encuentros y diálogos interculturales, es decir, reelaborar dialógicamente el pensamiento. En el caso de la televisión, la autora la presenta como un "enunciado concreto de comunicación mediatizada" y, desde la perspectiva aquí abordada, analizar la telenovela de esta manera es entenderla en el ámbito comunicativo de la cultura donde todo repercute en todo y donde las formas culturales viven en las "fronteras", generando así elementos híbridos (Machado, 2008, p. 162).

\section{LA TELENOVELA BRASILEÑA CORDEL ENCANTADO: POSICIONAMIENTO DEL OBJETO EMPÍRICO}

La telenovela Cordel encantado fue producida por la Rede Globo de Televisão entre el 11 de abril y el 23 de septiembre del 2011, exhibida a las 6 p. m. en la parrilla de programación. Con la autoría de Thelma Guedes y Duca Rachid, la obra contó con un total de 143 capítulos. Constituida con un tono de fábula, la historia se desarrolla en lugares ficticios como Seráfia (un reino europeo medieval lejano) y Brogodó (una ciudad típica de la provincia brasileña, del característico sertão de la región Nordeste del Brasil). Como dice Xavier (2011), la unión de dos mundos imaginarios tan distintos demostró ser una elección más que acertada por parte de los autores, ya que:

La unión de estos imaginarios estuvo representada por el amor entre la amable y pobre muchacha (Açucena/Aurora), una princesa de una casta real europea, pero criada como una cabocla brejeira por una pareja de campesinos, y un joven del interior, un verdadero sertanejo (Jesuíno), que, a su vez, no es reconocido como el hijo legítimo del cangaceiro (un ambiguo tipo de bandido) más temido y respetado de la región. Cuando la familia real llega de Europa, en busca de la heredera al trono, el amor de Açucena/Aurora y Jesuíno se ve amenazado. (párr. 5)

Otro punto relevante para entender la historia son los procesos de hibridación que impregnan la narrativa y la convierten en una trama particular en medio de tantas otras telenovelas brasileñas. Por tanto, pensar en la hibridación es pensar en la mezcla y en 
el mestizaje como procesos intrínsecos a la cultura y a la comunicación. Sin embargo, más que lidiar con fusiones, acomodaciones, criollizaciones, sincretismos, traducciones y adaptaciones, pensar en la hibridación es pensar también en sus resultados, en sus consecuencias e impactos (Silva, 2015). En lugar de entender la hibridación solo como la posibilidad del mestizaje, pensar de forma híbrida implica mayores exigencias de aquellos que pretenden entenderla como un proceso vivo y en constante cambio. Requiere cierto malestar, poca linealidad y el abandono de conclusiones que caen en meras relaciones de causa y efecto. Uno de estos requisitos es precisamente reconocer los elementos que componen la hibridación, es decir, elementos de su metaconstrucción y contexto, para que, solamente después, se enumeren los elementos resultantes de la mezcla, los elementos sui generis que surgen del proceso.

Es interesante notar que el estudio de la telenovela solo comenzó a ser visto con mayor seriedad dentro de los espacios académicos luego del paulatino desarrollo de la escuela latinoamericana de comunicación (especialmente debido a la presencia de la teoría de las mediaciones como uno de los hilos rectores de los estudios culturales latinoamericanos). Es decir, es después de esta renovación epistemológica en el continente que la mirada metodológica se ha movido de un lugar donde estaban presentes términos como "la manipulación, la masa amorfa y el espectador acrítico", a otro lugar donde las posibilidades de "apropiación y resignificación" por parte del espectador ganaron importancia en las discusiones entre comunicación, cultura y política (Martín-Barbero, 2009).

Lopes y Mungioli (2012) explican que en el tejido melodramático de Cordel encantado “[...] el discurso híbrido de la cultura oral en el país construyó una trama cautivadora basada en dos importantes matrices narrativas de la cultura brasileña: la literatura de cordel $^{3}$ y la telenovela" (p. 158). Y añaden que "[...] Cordel encantado nos enreda con la polisemia y plasticidad semiótica del texto audiovisual en un mundo de ficción con referencias directas e indirectas" a las diversas hibridaciones narrativas y culturales (p. 158). Y aquí la hibridación cultural se entiende, por concepto de García Canclini (2011), como el "[...] colapso de categorías y pares de oposición fijos", es decir, las formas en que los elementos culturales se fusionan y producen "culturas híbridas" produciendo "géneros impuros" (p. 283).

En esta obra hay una polisemia que va de la mano de las matrices culturales y los formatos industriales de la literatura cordel y la telenovela. Así, fue a partir de la

3 La literatura de cordel, según investigadores brasilianistas como Luyten (2000) y Curran (2009), puede entenderse, básicamente, como la producción de largos poemas narrativos denominados romances, causos o historias, que se imprimen en publicaciones seriadas o folletos de $32 \mathrm{o}$, raramente, 64 páginas. Estas obras hablan de amores, sufrimientos y aventuras, casi siempre, en un tono de heroísmo. Aunque está presente en muchas partes de Brasil, es en la región del Nordeste brasileño donde la literatura de cordel se muestra como especialmente vívida. 
formación de los personajes (arquetipos modulares) y la interdependencia entre ellos (elementos internos a la producción de sentido) que la narrativa serial de Cordel encantado pudo demostrar la hibridación cultural. Esto es, en esta ficción serial, el proceso de hibridación cultural tuvo lugar a partir del uso de elementos de la cultura popular (literatura de cordel, imaginario popular sobre cangaço $0^{4}$ brasileño, cuentos de hadas) y cultura erudita (referencias a la literatura francesa, elementos de la corte, mundo medieval) en una producción de cultura masiva (telenovela y sus narrativas lógicas), reelaborando los procesos de producción de sentido dentro de las materialidades dialógicas del lenguaje (Silva, 2015).

A través de las tramas que constituyen la narrativa del Cordel encantado, este artículo busca comprender cómo se configuran cuestiones de autoría y géneros discursivos, cómo se producen resignificaciones analíticas en el complejo tejido melodramático de la telenovela brasileña. Así, como posicionamiento metodológico, se coloca el concepto de extraposición como el punto de partida que establece las formas y relaciones entre el investigador y el objeto empírico investigado (en términos de aproximación, distancia y potencialidad de la mirada analítica).

\section{EXTRAPOSICIÓN: POSICIONAMIENTO METODOLÓGICO}

Al entrar en el campo de las reflexiones de Mijaíl Bajtín sobre la extraposición, es fundamental, en primer lugar, establecer que las bases de orientación de este pensamiento encuentran refugio en las formas de enlazar lo ético y lo estético como algo único para el autor. Un camino que, a lo largo de la trayectoria intelectual de Bajtín, se expresa como indisoluble y presente tanto en el proceso de construcción como en la lectura de las formas que el acabado estético adquiere sobre un objeto empírico.

Así, al pensar en la relación dialógica entre el yo y el otro en el mundo, Bajtín destaca un elemento muy peculiar en la relación de capturar la mirada de ese otro sobre mí y de mí sobre este otro. Señala que siempre habrá un exceso de la visión del otro sobre mí y de mí sobre el otro, de modo que yo nunca podré de manera global y totalizadora producir significado sobre sí mismo sin la contraparte del otro, este otro que tiene algo más, es decir, una visión en demasía, un exceso de visión.

4 El cangaço fue un complejo fenómeno de bandidaje del Nordeste de Brasil a finales del siglo XIX y principios del xx. Esta región de Brasil (el sertão) es conocida por su aridez y forma de vida dura, y en una forma de "bandidaje social" contra el gobierno, muchos hombres y mujeres decidieron convertirse en bandidos nómadas (cangaceiros), deambulando por el interior en busca de dinero, comida y venganza. Hasta hoy, las figuras de los cangaceiros son ambiguas: hay quienes los ven como villanos y quienes los ven como verdaderos héroes populares en el folclore brasileño (Proença, 1976; Cascudo, 1988). 
Este excedente constante de mi visión y mi conocimiento del otro está condicionado por el lugar que únicamente yo ocupo en el mundo: en este lugar, en este preciso momento, en un conjunto de circunstancias dadas, todos los demás están fuera de mí. La extraposición concreta que solo me beneficia a mí, y a todos los demás que me rodean, sin excepción, así como el excedente de mi visión que esta condiciona, en comparación con la de los demás [...]. (Bakhtin, 2000, p. 43)

"En consecuencia, lo que uno puede ver no es accesible para el otro y viceversa. Lo inaccesible no es, sin embargo, inexistente, de ahí la comprensión de Bajtín" del exceso de visión, a través de la relación dialógica, posibilitando algo que es capturado por una parte sobre otra en una relación de convivencia, explica Machado (2010, p. 277). Por tanto: "El otro que está fuera de mí es el que puede dar una imagen acabada y el acabado [estético] que, para Bajtín, es una especie de regalo del artista a su retratado", afirma Amorim (2006, p. 97).

Por esta razón, el término extraposición cobra sentido en este artículo a partir de la idea de una postura (espacio-tiempo) del investigador en relación con su objeto investigado. "La contemplación estética y un acto ético no pueden abstraer el hecho de que el sujeto de este acto y la contemplación artística ocupan un lugar concreto y único en la existencia", destaca Bakhtin (2000, p. 44). Es decir, el excedente de visión opera aquí como un gesto extraposicionado en el que el investigador se acerca a su trabajo, modelándolo, fragmentándolo, analizándolo y reconstituyéndolo en una forma de verlo más allá de las ideas puestas en escena y planteadas por los guionistas, productores, directores y todo el equipo de producción de la telenovela Cordel encantado.

Siguiendo este razonamiento, el término condensador de las ideas que explican la existencia de un excedente de visión es la palabra rusa vnenakhodimost', acuñada por Bajtín y que, según Todorov (1984, p. 99), significa literalmente "encontrarse del lado de afuera" o, brevemente, como señala Bubnova (2000, p. 33), "encontrarse afuera". Como uno de los primeros en llevar las discusiones bajtinianas a Occidente, Todorov traduce el término vnenakhodimost' al francés como éxotopie, una propuesta muy valiosa, según Amorim (2006), ya que, "desde el punto de vista de la enunciación y no de la lengua, la expresión forjada por Todorov es pertinente, porque sintetiza el significado que se produce en la obra de Bajtín, que es el de sentido de la ubicación de un lugar externo" (p. 96). En las traducciones al inglés, el término se convierte en outsideness, en italiano se lee como extralocacità, en portugués como exotopia y en español como extraposición (Bubnova, 2000, p. 33).

Para Machado (2010, pp. 277-278), el concepto de extraposición es controvertido, en gran medida, por las diversas interpretaciones y traducciones - consideradas como ejercicios metalingüísticos- que tiene la palabra vnenakhodimost'. Sin embargo, dice que, a pesar de las posibilidades truncadas de aplicar el término en función de la variabilidad de las traducciones, lo que no se puede perder de vista en la comprensión de 
extraposición es "[...] la noción de movimiento, el mayor valor de la categoría bajtiniana que tanto une como separa [...]". Bajtín organiza tal noción de movimiento (en el espacio-tiempo) de la siguiente manera:

El excedente de visión en relación con el otro individuo condiciona una determinada esfera de mi activismo exclusivo, es decir, un conjunto de esas acciones internas o externas que solo yo puedo practicar en relación con el otro, por debajo de las cuales son inaccesibles en el lugar que ocupa fuera de mí; tales acciones complementan al otro precisamente en aquellos elementos en los que él no puede completarse a sí mismo. (Bakhtin, 2000, p. 323)

En este sentido, Machado (2010) recuerda el entrelazamiento ético-estético propuesto por Bajtín al hacer el gesto extraposicionado como principio incorporado a sus concepciones de las relaciones arquitectónicas: "[...] me refiero a las formulaciones sobre el excedente de visión que Bajtín sitúa en el proceso de creación estética, particularmente del personaje" (p. 277). Esta particularidad, y no exclusividad, no excluye otros significados del término a mundos tan complejos como los presentados por ZoppiFontana (2005) al decir que el concepto de excedente de visión regresa insistentemente a los escritos bajtinianos y se utiliza para "[...] describir la relación entre el autor y los personajes de la novela, el yo y el otro en el evento comunicativo, el lector actual en relación con obras y culturas anteriores, y del científico (principalmente en las ciencias formales y naturales) frente al objeto de conocimiento" (p. 110). Más allá de la visión del científico de las ciencias naturales y su relación con la extraposición, Silva (2013) profundiza en la idea de que el excedente de visión:

Es, entonces, la diferencia entre dos miradas, entre dos puntos de vista. Tal movimiento también se puede observar en el trabajo de investigación (en ciencias humanas) en el que el investigador analiza el trabajo de otros sobre un determinado tema y trata de percibir la mirada de su sujeto sobre ese objeto investigado, volviendo a su "lugar exterior" para elaborar su texto (creación estética) sobre lo que logró plasmar en su investigación. En ese momento, para sintetizar lo que ve, el investigador utiliza sus valores, sus perspectivas, sus impresiones, su educación, para discutir lo que vio. (pp. 1-2)

Es decir, las voces aquí encontradas tienen en cuenta las formas en que la obra les afecta, o sea, qué y cómo la obra habla y se da a ver, a oír y a sentir para el investigador, siendo este último, sin embargo, el titular de un exceso de visión (analítica) que organiza estas voces y permite que los procesos de sentido sean inteligibles, además de los proyectados únicamente en el proceso original de exhibición, circulación y disfrute de la trama. Tal orquestación estética y ética de voces, permitida por el excedente de visión, hace posible al investigador el doble movimiento de acercarse y alejarse del objeto, empero, sin confundir las voces o incluso interferir en este proceso de análisis a tal punto que su propia voz analítica sea irreconocible o pierda la autoridad organizativa 
sobre el texto analizado: "Es importante notar que este diálogo no es simétrico y aquí reaparece el concepto de extraposición. El investigador [en el contexto de las humanidades] debe intervenir desde su posición externa" (Amorim, 2006, p. 100). Por tanto, la intervención del investigador y su autoridad organizativa no se puede perder de vista, precisamente, porque hay que ver el exceso que constituye el excedente de visión como una ventaja y no como una desventaja analítica.

Finalmente, esta relación extraposicionada entre el investigador y el objeto de análisis se entiende como una relación compleja, llena de hilos dialógicos, esto es, una relación legítima entre el "yo" y el "otro". Algo que, en palabras de Bubnova (2000), es más que valioso para el pensamiento bajtiniano: "El mundo de las relaciones entre el yo y el otro es generador de los valores inherentes a su interacción: principio interpersonal de una futura noción de ideología, que posteriormente el filósofo plantearía llevando la problemática de la otredad hasta la dimensión social" (p. 18).

Así, bajo una visión macro, el problema de pesquisa (visto aquí como tema de interés) está vinculado a la comprensión de los procesos de producción de sentido (Bakhtin, 2000, 2004; Bajtín, 2019), leídos desde la perspectiva de los estudios de televisión con un enfoque en los conceptos de extraposición, autoría y géneros discursivos. El problema de investigación (visto aquí como la línea de análisis) coloca a la telenovela Cordel encantado como la centralidad del análisis, es decir, bajo una visión micro. Aquí el objetivo explícito es comprender la forma en que se observan los procesos de producción de sentido dentro de este melodrama desde los principios dialógicos del exceso de visión, autor-creador, autor-persona y géneros discursivos secundarios.

Por fin, la estrategia metodológica (entendida como el medio de aproximación y comprensión del objeto empírico de análisis) se basa en la tensión entre la literatura bajtiniana y sus comentaristas, reubicándolos en el campo de la ficción televisiva. En otras palabras, este ensayo se basa metodológicamente en la investigación bibliográfica y en la observación empírica de la dramaturgia televisiva brasileña, observación analítica que toma en cuenta las particularidades estéticas de la narrativa televisiva (Balogh, 2002; Lopes, 2009), las cuestiones de autoría entre autores y directores (Souza, 2004), y el estilo televisivo (Rocha, 2016) que impregna la telenovela brasileña. En términos prácticos, es posible ver el problema de pesquisa, el problema de investigación y la estrategia metodológica como una tríada que interconecta y orienta la visión académica sobre el estudio de las telenovelas brasileñas y los estudios bajtinianos (figura 1). 


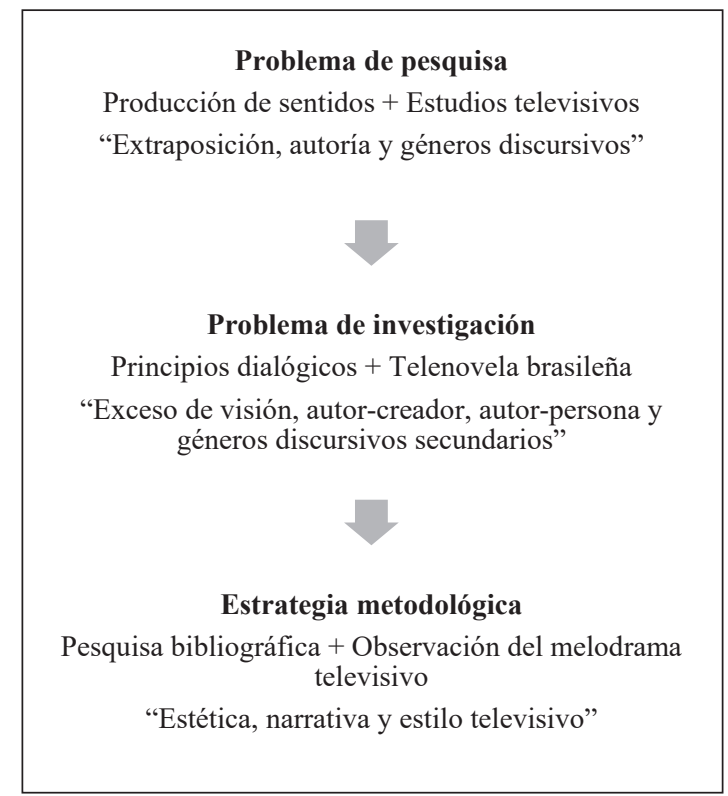

Figura 1. Problema de pesquisa, problema de investigación y estrategia metodológica

Elaboración propia

\section{EL AUTOR-PERSONA Y EL AUTOR-CREADOR: POSICIONAMIENTO ANALÍTICO I}

El concepto de autor y autoría en Mijaíl Bajtín siempre está impregnado de dialogismo, puesto que la notable visión de otredad en las interacciones entre individuos siempre se hará visible y necesaria. El debate sobre la cuestión de la autoría en la teoría bajtiniana, por tanto, se divide en autor-persona y en autor-creador, una división que dirige, a su vez, la futura comprensión del objeto estético bajo análisis.

El autor-persona es el ser físico, elemento del hecho ético y social de la vida (Faraco, 2008). Es el autor conocido, en una opinión común, como el que "escribe" la obra. En el caso de Cordel encantado, estos sujetos son las autoras Thelma Guedes y Duca Rachid. Sin embargo, en la discusión bajtiniana, el énfasis no está en la figura del sujeto-escritor, sino en la figura etérea del autor-creador. El autor-creador es una función estéticoformal de la obra, es decir, una parte inmanente del todo artístico (el objeto estético). Una parte que sostiene y, por ende, crea y da forma a la obra. Esta concepción de la autoría no se basa en el individuo que escribe, sino en el elemento externo que permite crear los personajes, sus características y el mundo en el que viven. 
Para intentar facilitar esta comprensión del autor-creador, es necesario visualizar dos formas de reflexión presentadas por Faraco (2008, p. 41): (1) Bajtín ve al autorcreador, en un principio, desde una posición axiológica (evaluativa) y que da unidad al conjunto artístico; y, un poco después, (2) el autor-creador es visto como la voz creativa (social) que también da unidad al conjunto artístico, pero, en esta visión, a partir de las voces sociales (heteroglosia) elegidas por el autor-persona.

La primera conceptuación sitúa al autor-creador como el responsable de crear una especie de "confrontación de mundos"; es decir, es su función, en el plano estético y en el acto creativo, confrontar el sistema de valores, normas, costumbres y tradiciones compartidas por la sociedad (el plano axiológico de la realidad vivida) con el sistema de valores propuesto dentro de la narrativa (el plano axiológico de la obra), o sea, los valores que delimitan los personajes y el carácter de cada uno de ellos, las situaciones, la resolución de problemas y el desarrollo de la historia. Desde esta perspectiva (en una mezcla de reflexión, refracción y reconstrucción de valores), y desde el autor-creador, el lector/espectador experimenta los dos planos axiológicos en contacto con la obra y, en consecuencia, reelabora nuevos mundos, nuevas axiologías.

En Cordel encantado es posible ver esto en la estructura arquetípica del cuadrilátero melodramático que está presente en esta telenovela; luego, en la narrativa sigue actuante el Justiciero (héroe), el Traidor (villano), la Víctima (chica dulce) y el Bobo (bufón) (Martín-Barbero, 2009, p. 168). Así, se puede poner a Jesuíno en la figura del Justiciero, a Timóteo como el Traidor, a Açucena/Aurora como la Víctima y, finalmente, al alcalde Patácio y la primera dama Ternurinha como representantes de la figura de los Bobos. Además de estos dos últimos personajes (que tienen un protagonismo más grande), se pueden encontrar muchos otros personajes en los papeles cómicos de Bobos como la reina madre Efigênia, el delegado Batoré, su hermana Neusa y su cuñado Farid, los amigos Quiquiqui y Setembrino, etcétera. Estos cuatro personajes centrales (Justiciero, Traidor, Víctima y Bobo) forman el cuadrilátero melodramático de esta telenovela, produciendo una mezcla de cuatro géneros intercambiables (la novela de acción, la epopeya, la tragedia y la comedia) que atraviesan toda la obra. En la telenovela en cuestión, el Justiciero se muestra como el personaje que, en el último momento, salva a la Víctima y castiga, finalmente, al Traidor. Su papel, en el transcurso de la trama, es mostrar los errores, revelar a todos la terrible cara del villano y dejar que "la verdad salga a la luz" (Martín-Barbero, 2009).

Esta visión del melodrama retratado en televisión, como heredero directo del folletín literario, tiene una conexión muy fuerte, por ejemplo, con los valores y roles sociales cristalizados y asignados a hombres y mujeres. La axiología de la realidad vivida (de forma muy discriminatoria) asume que, en un choque de género, le toca al buen hombre proteger, luchar contra el mal y acabar casándose con la mujer para formar una familia. Y 
la mujer, esa figura siempre pasiva, frágil y que vive por ósmosis de su relación conyugal, es solo el espacio privado del hogar. En cuanto a la axiología del objeto estético, con leves matices, esta valoración se replica ad infinitum y forma parte de muchas telenovelas.

Sodré (2010) presenta informaciones que corroboran este pensamiento cuando dice que en la telenovela (como en el folletín del siglo XIX) aún persiste un pensamiento de construcción arquetípica y estructural de la idea de familia tradicional, patriarcal, a través de una ideología de falsa modernización de la vida mediante el consumo de bienes comerciales, culturales y simbólicos. Esto, a su vez, acerca la telenovela (como un "romance familiar") a la comunidad y a las masas. Una narrativa que entrelaza la "escena familiar" con la "escena del video" y que vincula el flujo televisivo al flujo continuo de acciones sociales, como enfatiza Sodré (2010, p. 156).

La segunda conceptuación de Bajtín, por otro lado, ve al autor-creador en dos posiciones: la de refractada y la de refractor (Faraco, 2008). La primera es una posición valorativa recortada (refractada) por el autor-persona, una posición en la que el autor-creador es una proyección de las elecciones y valores del sujeto-escritor. A su vez, el autor-creador, como posición refractiva, es visto como el responsable de reorganizar (refractar) los acontecimientos de la vida (que es vivida tanto por el autor-persona como por el lector/espectador) y también de dar forma al contenido presentado en la obra. En otras palabras, es la voz social creativa la que organiza, trabaja, pule e inserta las múltiples voces sociales en la narrativa, dando unidad al objeto estético y coproduciendo sentido con quienes lo consumen.

En este enfrentamiento de mundos axiológicos, es posible ver que, además de tratar temas que forman parte de la vida de los espectadores o que al menos tienen verosimilitud narrativa y contextual, la apropiación cultural también se explica por el intercambio y aceptación de valores dominantes compartidos tanto por telenovelas como por el público. Y esta comunión pasa necesariamente por la figura del autor-creador, ya que tal configuración cultural creada y compartida por la sociedad dice mucho sobre el imaginario colectivo de un pueblo, sobre cómo se forman en este proceso de producción y recepción las clases sociales, las relaciones de género, el acceso al capital cultural y la convivencia con el entorno circundante. El discurso del autor-creador, por tanto, es siempre una "segunda voz" en relación con la primera y directa voz del escritor (Faraco, 2008, p. 40).

En el caso específico de las telenovelas brasileñas, Souza (2004, p. 14) destaca que las marcas autorales pueden concebirse en dos dimensiones: la externa y la interna. Mientras que la dimensión externa se ocupa de la noción de autor como un realizador (discutiendo el estatus de autor, la cadena de producción y las instancias de reconocimiento y consagración), a su vez, la dimensión interna se entiende como las marcas autorales presentes en el tejido teledramatúrgico (en términos de temas tratados, construcción de personajes, 
tratamiento del espacio-tiempo narrativo, etcétera). En este sentido, como afirma la investigadora, la cuestión de la autoría en la telenovela debe ir mucho más allá de la mera presencia del autor-persona en el proceso de realización de la obra:

Esto quiere decir que examinar las trayectorias de los directores en la historia de la producción de la telenovela nos permitirá ubicar el papel efectivo que han jugado en las interfaces entre las demandas del emisor y la necesaria satisfacción de los espectadores; entre el reconocimiento del autor/realizador y las elecciones estéticas, operativas y técnico-operativas que han configurado una marca estilística peculiar reconocible [...]. (Souza, 2004, p. 19)

Es lo que vemos en Cordel encantado que, si bien es una narrativa de fábula y donde hay un escape al realismo de la vida cotidiana, sin embargo, las voces sociales (heteroglosia) siguen presentes por parte del autor-creador refractado y refractivo. Aquí, el acuerdo ficticio en este "mundo parásito" que es la ficción (Eco, 1994, p. 91) llega a un nivel donde los espectadores comparten estos hechos fantásticos, reinos medievales, un sertão brasileño retratado por artistas de la literatura de cordel y una época tan mágica que es difícil ubicar el período preciso en el que se desarrolla la narración: Cordel encantado muestra, así, una narrativa perfectamente atemporal.

Aunque para Bajtín no es necesario comprender los procesos psicológicos involucrados en la creación por parte del autor-persona, sin embargo, es importante prestar atención al discurso de las autoras Thelma Guedes y Duca Rachid al comentar sobre esta atemporalidad de la narración en la edición en DVD de Cordel encantado (2013). En la entrevista, ellas hablan de cómo estaban pensando en crear nombres y personajes y, de repente, se dieron cuenta de que la historia era realmente un ejemplo televisivo de lo que sería la literatura de cordel.

[Duca Rachid] Es un cordel que al mismo tiempo permitía utilizar todo un repertorio de cuentos de hadas, "capa y espada", folletín, cuento de aventuras...

[Thelma Guedes] Incluso la historia de san Francisco, que fue medieval. Tomamos este universo que es atemporal. Lo que notamos, nos quedó claro, es que el sertão brasileño y el reino son universos atemporales. Ellos no cambian. [...]

[Duca Rachid] Como ocurre con el rey europeo y el rey cangaceiro. (TV Globo, 2013)

Bajtín también señala que lo que hace que una obra sea estéticamente creativa no consiste en la transcripción literal de las ideas del autor-persona en la voz social del autor-creador, como si ambos fueran uno. Por el contrario, "las ideas del autor-persona" (en el desplazamiento del lenguaje, es decir, en el proceso que trae múltiples voces sociales a la unidad conferida y organizada por la voz social del autor-creador) siempre deben ser transformadas, remodeladas y recreadas a partir de "imágenes artísticas de ideas" (Faraco, 2008, p. 40). El discurso de la directora Amora Mautner, siguiendo esta línea de razonamiento, muestra cómo es posible lograr algo similar en la esfera 
discursiva de Cordel encantado. En la misma entrevista con las dos autoras, la directora de esta telenovela comenta:

[Amora Mautner] Cuando leí la sinopsis, lo que encontré más difícil fue esto: estaba armando... ¿Cómo podríamos unificar una novela que tuviera un universo del cangaço brasileño y de la corte real europea? Porque supuestamente son dos cosas diferentes, ¿verdad? Pero, es como ustedes [Thelma y Duca] acabaran de decir, no lo son. (TV Globo, 2013)

Mientras las autoras, en la entrevista, hablan sobre la dinámica de su tipo de escritura por parejas, desde el intercambio de ideas y el juego de negociación al consenso, Duca Rachid comenta la participación de la directora Amora Mautner en la transformación de ideas del guion a la pantalla: tratamiento de la imagen, desde la estética cinematográfica, el arte y el vestuario hasta la representación de una escena de batalla específica que fue transformada por la mirada de la directora. Sobre la escena épica de invasión del rey Teobaldo (Serafín del Sur) al reino del rey Augusto (Serafín del Norte), Thelma Guedes dice:

[Thelma Guedes] Recuerdo perfectamente que habíamos hecho estas primeras escenas... Y un personaje dijo que estaban siendo atacados en las murallas... Porque nosotros, ni idea, pensamos que era más fácil pelear en las murallas y tal... [risas] Cuando vimos la "idea" de Amora de cómo hacer eso, de acercar los dos ejércitos [en plan general], esa imagen...

[Duca Rachid] ¡Fue genial!

[Thelma Guedes] ¡Más cinematográfico que el cine! (TV Globo, 2013)

Se plantea, entonces, la cuestión de una tercera entidad que forma parte de la figura etérea de autor-creador, representada en la obra, ahora, por la directora Amora Mautner, ya que es a partir de la remodelación realizada por la directora que tomaron forma las escenas y los significados intra e intercapitulares.

Como explica Souza (2004), el papel del director en las telenovelas brasileñas ha sido sumamente importante para la comprensión de las marcas autorales en las obras: "Asociado al crecimiento en el rol de dirección, es perceptible la tendencia de los escritores a elegir cada vez más una alianza constante con el director, que será el responsable del producto final [...]" (p. 30). Esto es algo que también se nota en la asociación de las escritoras Thelma Guedes y Duca Rachid con el trabajo de la directora Amora Mautner en otras telenovelas, además de Cordel encantado, por ejemplo, Cama de gato (2009) y Joia rara (2013), ambas producidas y también exhibidas en la Rede Globo de Televisão.

De esta manera, especialmente a partir de la década de los ochenta, prosigue Souza (2004), la actuación de la dirección en la telenovela brasileña comienza a plantear la urgencia de "definir un lenguaje audiovisual propio del género" (p. 30). Y eso es lo que 
nos lleva a otra (breve) discusión que actualmente se encuentra en el nivel de los géneros discursivos secundarios, que, a su vez, se leen desde la teledramaturgia brasileña.

\section{LOS GÉNEROS SECUNDARIOS DESDE LA TELEVISIÓN: POSICIONAMIENTO ANALÍTICO II}

Los géneros discursivos se presentan en Mijaíl Bajtín como esferas o usos del lenguaje, ya que las interacciones dialógicas presuponen procesos productivos lingüísticos. Divididas en géneros primarios y secundarios, estas esferas discursivas son leídas por Bajtín en la novela, en la prosa y, en el caso concreto que aborda este artículo, posiblemente también en la comunicación mediatizada de la televisión. Los géneros primarios se ven desde la perspectiva de la comunicación cotidiana, las conversaciones interpersonales, y están más directamente vinculados a la prosificación de la cultura (Morson y Emerson, 2008). Los secundarios, según Machado (2008, p. 155), son más complejos y se producen a partir de códigos culturales elaborados, como la novela, los géneros periodísticos, el ensayo y, en esta lectura, la telenovela brasileña.

Así, afirmar la naturaleza dialógica del lenguaje es entender que existen varios tipos de signos y sus arreglos sufren desplazamientos permanentes que se retroalimentan en secuencias intertextuales e interdiscursivas. Estas secuencias funcionan en sus contextos histórico-sociales como fuentes de significado que se producen dialógicamente, como los medios de comunicación contextualizados en su tiempo y espacio. También vale la pena aclarar que, para Bajtín, el dialogismo de interacción solo puede entenderse desplazando el concepto de sujeto. El sujeto pierde el rol de centro y es reemplazado por diferentes voces sociales, que lo convierten en un sujeto histórico e ideológico ubicado en un tiempo y espacio determinado.

Bajtín cree que la palabra debe verse como un signo y, como tal, debe ser percibida como originaria de la relación social, ya que está presente en todos los actos de comprensión e interpretación. De esta forma, como los signos median la relación del hombre con su realidad, toda la actividad mental del sujeto puede expresarse en forma de signos, expresándose a través de lenguajes verbales o no verbales, o incluso por otros medios que surjan del discurso interno. En el caso de las telenovelas y otras obras de ficción seriadas en televisión, hay que considerar las especificidades de los contextos de producción, circulación y distribución de las obras teledramatúrgicas: "El género secundario, cuando actúa en la producción de determinados discursos, tiene en cuenta tanto el estilo de las formaciones sociales con prácticas de identidad, así como el estilo de formas activas de economía, como patrocinadores, canal televisivo, etcétera", afirma Pisa (2013, p. 22).

Cordel encantado, al trabajar con innumerables matrices y arquetipos de la cultura popular, erudita y masiva, permite el surgimiento de procesos de producción de sentido 
que hibridan tales matrices y arquetipos. Por tanto, esta telenovela brasileña se puede leer como un género discursivo secundario. En otras palabras, es posible observar que se presenta, en una lectura potencial de las afirmaciones de Machado (2008), como una obra donde "todo enunciado es un eslabón de una cadena, muy complejamente organizada, de otros enunciados" (p. 154) que, en consecuencia, dan lugar al "surgimiento de híbridos".

De igual manera, la prosificación, en la comprensión bajtiniana, estaría vinculada a la revitalización de la prosa en la cultura de la civilización occidental. Luego, acerca las formas discursivas de la comunicación interactiva y favorece la valorización de las acciones cotidianas de los hombres corrientes y de sus declaraciones banales, en contraposición al papel privilegiado que siempre ha ganado la poética en los estudios lingüísticos desde Aristóteles (Machado, 2008, pp. 153-154).

Desde esta perspectiva, al entender la telenovela como una forma de "crónica diaria" basada principalmente en el diálogo de los personajes y en escenas que se ubican en la vida cotidiana, es posible verla como un género secundario en el que la prosificación cultural también actúa en los procesos de producción de sentido. 0 , como señala la investigación de Pisa (2013), es necesario observar cómo la televisión y sus productos necesitan ser resignificados a la luz de los conceptos bajtinianos, ya que:

Los géneros secundarios se intercalan en la producción de los géneros televisivos y los géneros primarios son asimilados por los secundarios, puesto que los relatos de la vida cotidiana, al insertarse en el género secundario, se desconectan del ámbito de la vida cotidiana, pierden su conexión directa con la realidad, dejan de ser cotidianos y pasan a formar parte de otra dimensión enunciativa e ideológica. (Pisa, 2013, p. 25)

De este modo, pensar en la producción de sentido, como lo recuerda Volóchinov (2017), revela una discusión que se interesa por desvelar cómo se puede comprender plenamente la palabra, al hacer una diferencia, en este proceso, entre las nociones de tema y de significado. Así, tendríamos la concepción de que un significado definido y único (un significado unitario) es una propiedad que está a cargo de cada enunciado en su conjunto. Se llega a lo que podemos llamar el sentido de la enunciación completa como tema: el tema debe ser único, si no, no hay forma de diferenciar la enunciación.

Dicho esto, es posible notar que el tema de la enunciación es en realidad, así como la enunciación misma, individual y no reiterativo; es decir, se presenta como la expresión de una situación histórica concreta, contextual y no universal que dio lugar a la enunciación (Volóchinov, 2017). Enunciados y enunciaciones que están rodeados de condiciones lingüísticas marcadamente diversas e imbuidos de voces sociales (heteroglosia) que los configuran tal como son. 
Sin embargo, pensar la cuestión de los procesos de construcción de sentido y los géneros secundarios del discurso sin tener en cuenta la especificidad de la cultura y la estética televisivas no permite que una mirada comunicacional completa al Cordel encantado se explicite en un artículo como este. Aunque, para muchos, la televisión rara vez se considera "relevante" cuando el tema de la discusión se centra en la estética o no se considera lo suficientemente "serio" como para que se lleve a cabo una discusión de este tipo (Fahle, 2006, p. 190), aun así, es necesario que la estética televisiva pase a primer plano como un espacio de discusión fundamental sobre la comunicación y las gramáticas televisivas.

Por lo tanto, como indica Rincón (2007), la televisión "es cultura en sí misma, más que por los contenidos 'culturosos' que transmita" (p. 30). Esto es lo que también destacó Colombo (1976, p. 96), hace muchas décadas, al discutir lo que él llama una cultura de comunicación visual en la televisión como algo de gran importancia para el entendimiento de este medio y de sus producciones. Y, finalmente, entender los géneros discursivos bajtinianos como manifestaciones de la cultura posibilita leerlos como "dispositivos para organizar, intercambiar, difundir, almacenar, transmitir y, sobre todo, crear mensajes en contextos culturales específicos" (Brait, 2008, p. 88). En otras palabras, al igual que en Cordel encantado y su reelaboración de otras historias y narrativas, los géneros discursivos también viven en el presente, pero recuerdan siempre su pasado (Machado, 2008, p. 158).

\section{CONCLUSIONES}

La lectura de la telenovela Cordel encantado, a partir las concepciones de autoría, revela al menos tres conclusiones en este artículo: (1) la distinción entre autor-persona y autorcreador se mantiene (y se refuerza) en esta narrativa; (2) la conformación de arquetipos y matrices culturales presentes en la historia (a través de procesos de hibridación) converge con la unidad creativa de las múltiples voces sociales leídas en otros enunciados; y (3) se adjunta la figura del director a la lista de sujetos-escritores (autor-persona) por el hecho de dar visualidad y materialidad a las ideas de guion de los dos autores y, así, estas tres entidades forman la figura etérea del autor-creador en esta telenovela.

En el campo de los géneros discursivos, es posible afirmar que ver al Cordel encantado como un género secundario basado en códigos culturales complejos y elaborados permite constatar que esta telenovela es un elemento de prosificación de la cultura y, más aún, que como manifestación cultural ubicada en su contexto productivo receptivo, impregna las relaciones de identificación y de proyección. Al hacerlo, la telenovela brasileña produce roles intercambiables entre quienes consumen la narrativa, en un desplazamiento que denota el potencial cocreativo del espectador en relación con el emisor. Esta última característica se ve fortalecida por el acuerdo ficticio y por la suspensión de la incredulidad en una narrativa que posee el tono de fábula. 
Metodológicamente, el concepto bajtiniano de extraposición resultó ser fundamental en la relación entre el investigador y el objeto investigado. Es decir que, en el caso de la telenovela, en cuanto producto cultural complejo con un rico acabado estético, se entiende que el excedente de visión es necesario en la distancia (y en el adecuado acercamiento) entre el analista y la obra que es objeto de estudio. A su vez, cabe mencionar la posición de Amorim (2006), compartida en este artículo: "El acabado estético no tiene sentido de aprisionamiento; al contrario, es un acto generoso de quienes dan desde sí mismos. Dar desde tu puesto, dar lo que solo tu puesto te permite ver y entender" (p. 97).

De igual manera, el concepto de dialogismo se retoma en este campo como el principio teórico bajtiniano que concierne a las relaciones que se establecen entre el yo y el otro en los procesos discursivos históricamente establecidos por los sujetos, quienes, a su vez, se establecen a sí mismos y son instigados por estos discursos. Por lo tanto, opera la lógica en la que el discurso de un sujeto solo tiene lugar y crea sentido si se piensa en relación con los otros, y en esta interacción el acto comunicativo es tanto hacer como responder preguntas. Por tanto, es en esta relación entre el yo y la voz del otro donde surgen las dinámicas de interacción e interactividad, elementos fundamentales del dialogismo considerados desde el ángulo de los estudios comunicacionales.

Esto significa superar visiones de un modelo reduccionista y funcionalista que tiene un carácter unidireccional y coloca el papel de la recepción como actividad pasiva en la resignificación de los mensajes. Significa un redimensionamiento del espacio comunicativo, reajustando los roles de emisores y receptores a una dinámica relacional de coautores, de cocreadores. De este modo, interactuar se convierte en algo más que enviar y responder mensajes, ya que los sujetos pasan a formar parte de un proceso de relaciones interconectadas por hilos dialógicos presentes en la trama de la telenovela $y$, por supuesto, en las muchas tramas de las mediaciones socioculturares que se establecen desde ahí.

Por consiguiente, se considera que el emisor tiene la potencialidad de crear espacios en los que se conjugan los signos para ofrecer un conjunto de posibilidades de articulación de redes y conexiones, y que el receptor puede interferir en ellas modificándolas, asociándolas o resignificándolas, frente a la polisemia y ambigüedad, por aproximaciones sucesivas, de ida y vuelta, ya que los significados atribuidos no siempre son los que pretende el autor (sea él el autor-persona o el autor-creador).

En síntesis, este artículo trató de traer una posible conexión teórica y metodológica entre el pensamiento de Mijaíl Bajtín y el estudio de la telenovela brasileña, que, desde un punto de vista académico, se ve como un producto cultural dotado de un complejo acabado estético. Más que nunca, lo que ha demostrado este artículo es que es necesario entender la telenovela brasileña como un objeto mediático ubicado social e históricamente en la esfera discursiva de la comunicación audiovisual y, por tanto, una lectura 
basada solo en juicios de valor o en discusiones antiguas y enclaustradas acerca de la existencia de una "alta" y "baja" cultura, por fin, se vuelven inviables dada la riqueza estilística y estética del producto analizado.

\section{REFERENCIAS}

Aires, A. B. (2013). Estratégias de renovação da telenovela: a produção de uma estética da diferença em Cordel Encantado (disertación para la maestría en Comunicación y Consumo). Escola Superior de Propaganda e Marketing, São Paulo, Brasil. https://tede2.espm.br/handle/tede/126

Amorim, M. (2006). Cronotopo e exotopia. En B. Brait (Ed.), Bakhtin: outros conceitos-chave (pp. 95-114). Contexto.

Bajtín, M. (2019). La novela como género literario (Ed. L. Beltrán Almería; Trad. C. Ginés Orta). Editorial Universidad Nacional; Real Sociedad Menéndez Pelayo; Prensas de la Universidad de Zaragoza.

Bakhtin, M. (2000). Estética da criação verbal (3.a ed.). Martins Fontes.

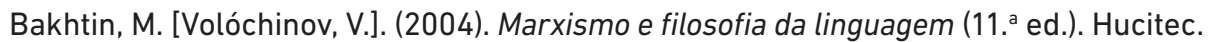

Balogh, A. M. (2002). 0 discurso ficcional na TV: sedução e sonho em doses homeopáticas. Edusp.

Borkosky, M. M. (2016). Telenovela nueva: nuevas lecturas. Corregidor.

Brait, B. (2008). Estilo. En B. Brait (Ed.), Bakhtin: conceitos-chave (pp. 79-102). Contexto.

Bubnova, T. (2000). Prólogo. En M. Bajtín, Yo también soy (fragmentos sobre el otro) (pp. 11-26). Taurus.

Cascudo, L. C. (1988). Dicionário do folclore brasileiro. Itatiaia.

Colombo, F. (1976). Televisión: la realidad como espectáculo. Gustavo Gili.

Costa, C. (2000). A milésima segunda noite: da narrativa mítica à telenovela - análise estética e sociológica. Annablume.

Eco, U. (1994). Seis passeios pelos bosques da ficção. Companhia das Letras.

Faraco, C. A. (2008). Autor e autoria. En B. Brait (Ed.), Bakhtin: conceitos-chave (pp. 37-60). Contexto.

Fahle, O. (2006). Estética da televisão: passo rumo a uma teoria da imagem da televisão. En C. Guimarães, B. S. Leal y C. C. Mendonça (Orgs.), Comunicação e experiência estética (pp. 190-208). Editora UFMG. 
García Canclini, N. (2011). Culturas híbridas: estratégias para entrar e sair da modernidade. EDUSP.

Hartmann, F. (2007). A voz e o discurso interior na obra de Mikhail Bakhtin. Calidoscópio, 5(2), 77-83. http://revistas.unisinos.br/index.php/calidoscopio/article/view/5628

Kehl, M. R. (1986). Eu vi um Brasil na TV. En A. H. Costa, I. F. Simões y M. R. Kehl (Eds.), Um país no ar: história da TV brasileira em 3 canais (pp. 167-323). Brasiliense/Funarte.

Lemos, L. P., y Rocha, L. L. (2021). Fiç̧ão seriada: estudos e pesquisas. Jogo de Palavras; Provocare Editora.

Lopes, M. I. V. (2009). Telenovela como recurso comunicativo. MATRIZes, 3(1), 21-47. https:// doi.org/10.11606/issn.1982-8160.v3i1p21-47

Lopes, M. I. V., y Lemos, L. P. (2020). Brasil: tempo de streaming brasileiro. En M. I. V. Lopes y G. O. Gómez (Eds.), O melodrama em tempos de streaming. Anuário OBITEL 2020 (pp. 83-116). Sulina.

Lopes, M. I. V., y Mungioli, M. C. P. (2012). Brasil: a "nova classe média" e as redes sociais potencializam a ficção televisiva. En M. I. V. Lopes y G. O. Gómez (Eds.), Transnacionalização da ficção televisiva nos países ibero-americanos. Anuário OBITEL 2012 (pp. 129-186). Sulina.

Machado, I. (2008). Gêneros discursivos. En B. Brait (Ed.), Bakhtin: conceitos-chave (pp. 151-166). Contexto.

Machado, I. (2010). A questão espaço-temporal em Bakhtin: cronotopia e exotopia. En Paula, L.; Stafuzza, G. (orgs.). Círculo de Bakhtin: teoria inclassificável (pp. 203-234). Mercado de Letras.

Martín-Barbero, J. (2009). Dos meios às mediações: comunicação, cultura e hegemonia. Editora UFRJ.

Mazziotti, N. (1993). El espectáculo de la pasión. Las telenovelas latinoamericanas. Colihue.

Morson, G. S., y Emerson, C. (2008). Mikhail Bakhtin: criação de uma prosaística. Edusp.

Pisa, L. F. (2013). 0 gênero discursivo televisivo: reflexões sobre Malhação. Revista Hispeci \& Lema On-Line, 4(4), 14-27. http://www.unifafibe.com.br/revistasonline/ arquivos/hispecielemaonline/sumario/26/22112013154206.pdf

Proença, I. C. (1976). A ideologia do cordel. Imago.

Ribeiro, R. R., y Silva, A. L. (2014). Imaginação melodramática, cultura e estética televisivas: uma leitura triádica do folhetim na TV. Culturas Midiáticas, 7(1), 16-29. https://periodicos.ufpb.br/index.php/cm/article/view/19736 
Rincón, 0. (2007). Televisión e identidades: hacia una construcción (+) diversa de la realidad. En E. Carrasco Pirard y N. Rampaphorn (Eds.), Televisión y cultura, una relación posible (pp. 25-43). LOM Ediciones; Consejo Nacional de la Cultura y las Artes.

Rocha, S. M. (2016). Estilo televisivo e sua pertinência para a TV como prática cultural. Insular.

Santa Cruz, E. (2003). Las telenovelas puertas adentro. El discurso social de la telenovela chilena. LOM Ediciones.

Schiavoni, J. E. (2021). Telenovela: elementos identitários em vinheta de abertura. Intexto, 52, 1-21. https://doi.org/10.19132/1807-8583202152.86740

Schnaiderman, B. (1983). Turbilhão e semente. Ensaios sobre Dostoiévski e Bakhtin. Duas Cidades.

Sériot, P. (2015). Volosinov e a filosofia da linguagem. Parábola Editorial.

Silva, A. L. (2015). Uma leitura dos processos de hibridização cultural na ficção seriada televisiva: análise dos personagens e suas inter-relações na telenovela "Cordel encantado" (2011) (disertación para la maestría en Comunicación). Universidade Federal do Paraná, Curitiba, Brasil. https://acervodigital.ufpr.br/ handle/1884/40876

Silva, D. B. (2013). Excedente de visão: um olhar exotópico através das artes. Comunicación presentada en el I Seminário de Estudos de Linguísticos e Literários. Cuiabá, Mato Grosso, Brasil. http://periodicoscientificos.ufmt.br/ojs/index.php/revdia/issue/ view/208/showToc

Sodré, M. (2010). Reinventado a cultura: a comunicação e seus produtos. Vozes.

Souza, G. T. (2002). A construção da metalinguística: fragmentos de uma ciência da linguagem na obra de Bakhtin e seu círculo (tesis doctoral). Universidade de São Paulo, Brasil. https://www.teses.usp.br/teses/disponiveis/8/8139/tde-17092002-120415/ pt-br.php

Souza, M. C. J. (2004). Analisando a autoria das telenovelas. En M. C. J. Souza (Ed.), Analisando telenovelas (pp. 11-52). E-papers Serviços Editoriais.

Todorov, T. (1984). Mikhail Bakhtin: the dialogical principle. University of Minnesota Press.

TV Globo (produtor). (2013). Entrevista: Thelma Guedes, Duca Rachid e Amora Mautner. En Cordel encantado [DVD]. TV Globo/Som Livre.

Vauthier, B., y Cátedra, P. (Eds.). (2003). Mijaíl Bajtín en la encrucijada de la hermenéutica y las ciencias humanas. SEMyR (Seminario de Estudios Medievales y Renacentistas - Sociedad de Estudios Medievales y Renacentistas). 
Volóchinov, V. (2017). Marxismo e filosofia da linguagem: problemas fundamentais do método sociológico na ciência da linguagem. Editora 34.

Xavier, N. (2011). Cordel encantado. Bastidores. Teledramaturgia. http://teledramaturgia. com.br/cordel-encantado/

Zbinden, K. (2006). Bakhtin between East and West. Cross-cultural transmission. LegendaRoutledge.

Zoppi-Fontana, M. G. (2005). 0 outro da personagem: enunciação, exterioridade e discurso. En B. Brait (Ed.), Bakhtin: dialogismo e construção de sentido (pp. 115-128). Editora Unicamp. 